\title{
The contribution of neuroscience to consumer research: A conceptual framework and empirical review
}

Céline Solnais ${ }^{\mathrm{a}}$, Javier Andreu-Perez ${ }^{\mathrm{b}}$, Juan Sánchez-Fernández ${ }^{\mathrm{a}}$, Jaime Andréu-Abelac ${ }^{\mathrm{c}}$.

\author{
${ }^{a}$ Department of Marketing and Market Research, Faculty of Economic and Business Sciences, University \\ of Granada, Campus Universitario de La Cartuja, s/n, \\ 18071 Granada, Spain \\ ${ }^{\mathrm{b}}$ Hamlyn Centre, Institute of Global Health Innovation, Imperial College London, South Kensington \\ Campus, London SW7 2AZ, United Kingdom \\ ${ }^{c}$ Faculty of Political Sciences and Sociology, University of Granada, C/Rector López Argüeta,s/n, 18071 \\ Granada, Spain
}

\begin{abstract}
Following the development of advanced neuroimaging techniques, the growing interest in studying the brain's response to marketing stimuli resulted in the birth of consumer neuroscience within the field of neuroeconomics. However, marketing scholars have remained reluctant to adopt the techniques of neuroscience and there is still uncertainty about the capacity of neuroimaging data to provide useful findings about consumer psychology and behaviour. In order to clarify the current scope and contribution of consumer neuroscience, we first develop a semantic cluster analysis of the boundaries of the field, followed by a comprehensive empirical review from 34 selected studies. We propose a novel approach to classify findings and facilitate the assessment of evidence around the topics of decision- making, rewards, memory and emotions. Finally, we discuss the possible role of several brain mechanisms in the processing of marketing stimuli as well as obstacles to the integration of these findings with classical consumer behaviour theories. We conclude that the contribution of neuroimaging remains too limited to replace existing consumer research techniques and provide recommendations for future research.
\end{abstract}

Key words: neuroeconomics; consumer neuroscience; consumer research; consumer behaviour; neuromarketing.

JEL classification: M30; D87.

PsycINFO classification: 2500; 2520; 3900; 3920; 3940. 


\section{Introduction}

The concept of applying neuroscientific techniques to the study of consumers' emotional and cognitive responses has sparked growing interest in recent years. In fact, the use of psychophysiological techniques is not new in consumer research since pupillary dilation and electrodermal response measures have been applied since the 1960s, later followed by eyetracking and heart rate (Wang \& Minor, 2008). Likewise, electroencephalography started to be used in marketing-related studies in the early 1970s (e.g. Krugman, 1971). The measurement of electrical brain waves has also focused on analysing the amplitude and peak latency of P300, a positive potential that is emitted by the brain when a significant or relevant stimulus is recognised, which can inform about cognitive responses such as working memory (Ma, Wang, Shu, \& Dai, 2008).

However, these initial approaches have not been able to fully meet expectations due to methodological issues such as the difficulties to evaluate the valence of consumers' reactions (Kenning, Plassmann, \& Ahlert, 2007). Therefore, it is not until further technology developments and the emergence of advanced imaging techniques that the application of neuroscience to the study of consumer behaviour took off. In particular, functional magnetic resonance imaging (see Section 3.1) has al- lowed the observation of the specific components of the brain's functional architecture activated in response to marketing stimuli (Erk, Spitzer, Wunderlich, Galley, \& Walter, 2002). This resulted in the birth of a new interdisciplinary field commonly referred to as "consumer neuroscience". Professor Ale Smidts is known as the first to name the use of neuroscientific techniques by the marketing discipline in 2002. As opposed to the original term of "neuromarketing", the name of "consumer neuroscience" was qualified as more appropriate (Hubert, 2010) while "neuromarketing" was defined as the practical implementation of the knowledge brought by consumer neuroscience for managerial purposes (Hubert \& Kenning, 2008). As a subfield of neuroeconomics, consumer neuroscience is "the study of the neural conditions and processes that underlie consumption, their psychological meaning, and their behavioural consequences" (Reimann, Schilke, Weber, Neuhaus, \& Zaichkowsky, 2011, p. 610). By focusing on those brain mechanisms involved in consumers' decision-making processes, consumer neuroscience is part of the wide spectrum of research carried out within the broader field of decision neuroscience, which has generated a variety of issues and interests in recent years (Hansen, Kenning, \& Plassmann, 2010; e.g. Jamison \& Wegener, 2010; Moreira, Matsushita, \& Da Silva, 2010; Ramsøy \& Skov, 2010).

Several advantages of neuroimaging might explain its apparent attractiveness for applications in consumer research. Most importantly, neuroscientific methods can enable to 
Solnais, C., Andreu-Perez, J., Sánchez-Fernández, J., \& Andréu-Abela, J. (2013). The contribution of neuroscience to consumer research: A conceptual framework and empirical review. Journal of Economic Psychology, 36, 68-81.

identify the underlying processes responsible for the behaviour of interest, as similar behaviours may result from different psychological processes (Sanfey, Rilling, Aronson, Nystrom, \& Cohen, 2003). In particular, neuroscience could help to understand the role of inner emotional responses, which may play an important part in the economic decision-making process as illustrated in Sanfey et al. (2003). In this aim, neuroscientific techniques provide objective physiological data, since subjects cannot or very little influence these measurements (Camerer, Loewenstein, \& Prelec, 2005), as opposed to self-report respondents who may not accurately assess their preferences and decisions (Petty \& Cacioppo, 1983) due to, for example, the tendency to provide socially accepted answers (Nighswonger \& Martin, 1981). In addition, neuroimaging enables to simultaneously track consumers' neural responses at the same time as the marketing stimulus of interest is processed, thus eliminating the risk of recall bias commonly associated with self-re- port measures (Sudman \& Bradburn, 1973). Altogether, this has raised an initial hope in the literature that neuroimaging data could help to explain what is happening inside the "black box" (Fugate, 2007), a classical notion that posits that consumers' minds remain unobservable to researchers (Engel, Kollat, \& Blackwell, 1968; Howard \& Sheth, 1969; Nicosia, 1966).

However, the future capacity of modern neuroimaging technologies to be more effective in answering this question than older psychophysiological approaches is still uncertain. Despite the growing number of empirical studies in recent years, there is continuing scepticism on whether neuroscience methods could indeed bring useful findings to consumer research and, in general, enable better predictions of economic behaviour (Addie, 2011; Camerer, 2007; Lee, Broderick, \& Chamber- lain, 2007). In parallel, the difficulty for economic and marketing scholars to adopt the specialised techniques and knowledge of the distant field of neuroscience raises a challenge to translate neuroimaging data into accurate and meaningful results (Hubert, 2010). As a growing set of findings is being provided, a complete research synthesis is needed at this stage beyond introductory reviews so the current state of empirical evidence can be clarified. In this context, the general purpose of our research is to define the frontiers and scope of the recent field of consumer neuroscience based on existing findings. Specifically, we first carry out a semantic cluster analysis in order to provide a conceptual overview of the field. We then report a comprehensive empirical review based on 34 studies spanning from 2001 to 2012. This introduces a novel classification approach to facilitate comparisons between findings and assess the state of the art around four core topics at the basis of consumer behaviour: decision-making, rewards, memory and emotions. Finally, we discuss the advances and limitations to the contribution of neuroscience from a consumer research perspective and provide recommendations for future research. 


\section{The neuroscientific foundations of consumer neuroscience}

The use of advanced neuroimaging techniques allows an increasingly precise identification of neural responses across specific brain regions. The importance of such anatomical localisation is due to the potential relevance of certain brain regions for consumer research given the role they play in different cognitive and emotional functions (Table 1). In this section we review the neuroscience literature in order to provide a theoretical framework of the key brain mechanisms of interest for consumer research.

\subsection{Decision-making}

A central question within consumer research is about consumer decision-making and the way consumers assess different product alternatives based on perceived benefits and costs. Several regions of the prefrontal cortex (PFC), situated in the frontal lobe of the brain, might be related to this question due to the critical role they play in the underlying processes of human decision-making. Specifically, there is evidence of both the orbitofrontal cortex (OFC) and the ventromedial prefrontal cortex (VMPFC) being involved in the processing of different alternatives and potential outcomes through the assessment of their (perceived) value (Tremblay \& Schultz, 1999; Daw, O’Doherty, Dayan, Seymour, \& Dolan, 2006). In particular, the OFC is associated with the evaluation of trade-offs and the expected capacity of outcomes to satisfy one's needs (Wallis, 2007). It also plays a central role in making choices about appropriate behaviours, especially when one is faced with unpredictable situations (Elliott, Dolan, \& Frith, 2000). Finally, the dorsolateral prefrontal cortex (DLPFC) also plays a critical role in decisionmaking as it is known for being involved in cognitive control over emotions (Rilling, KingCasas, \& Sanfey, 2008). In particular, it is involved in the control of impulses for complying with social norms while the ventrolateral prefrontal cortex (VLPFC) could play a role in motivating this social norm compliance by representing the threat of punishment from others (Rilling \& Sanfey, 2011). Interestingly, the cognitive effort in the PFC appears to be lower when a sure gain is expected com- pared with risky decisions (Gonzalez, Dana, Koshino, \& Just, 2005). Measuring the activity of these regions may therefore provide useful insights about the neural foundations of consumer choices and marketing constructs such as perceived value.

\subsection{Reward processing}

Another set of brain regions of particular interest for consumer research consists of those part of the reward system of the brain. They indeed respond to subjectively attractive rewards 
such as food (Berridge, 1996), money (Knutson, Adams, Fong, \& Hommer, 2001) and drugs (Wise \& Rompré, 1989). In other words, an attractive product design or a favourite brand that is able to act as a rewarding stimulus within consumers' brains may trigger the psychological motivations that influence purchase behaviour. A way of monitoring the processing of rewarding stimuli is to measure the activation of the striatum, a striped mass of white and grey matter located in the basal ganglia inside the forebrain. Although a major function of the striatum is movement planning and control, it also plays a role in the reward system of the brain. Thus, there is evidence of the role of the striatum and its components (putamen, caudate nucleus and nucleus accumbens) in the evaluation of actual re- wards with respect to one's expectations (Knutson \& Wimmer, 2007) and the influence of social factors on the rewardrelated activity in this region (Fliessbach et al., 2007). Also part of the reward system is the ventral tegmental area (VTA). It is responsible for transmitting dopamine, a neurotransmitter, to other brain regions, thus enabling the modulation of decision-making and playing a role in goalseeking behaviours (Fields, Hjelmstad, Margolis, \& Nicola, 2007).

\subsection{Approach and withdrawal motivation}

According to the neuroscience literature, human behaviour relies on two motivational systems, whether behaviour is motivated by an anticipated desirable outcome or a possible aversive outcome. Specifically, EEG studies have provided important empirical support about the left frontal cortex being involved in a system that motivates approach behaviour (Davidson, 2004). Reversely, the right frontal cortex has been shown to be involved in a system that motivates withdrawal behaviour (Davidson, 2004). Thus, studies suggest that a greater activity in the left frontal region with respect to the right frontal region is associated with approach motivation, which is in turn generally associated with positive emotions, although the latter should be applied with caution as not always the case (Harmon-Jones, 2003). On the contrary, a relatively greater activity in the right frontal region is associated with withdrawal motivation, which is in turn generally associated with negative emotions (Harmon-Jones, 2003). Consequently, the interest for consumer research is the possibility to monitor the left-right asymmetry of consumers' brains so as to interpret their motivational responses to marketing stimuli and thus potentially infer the attractiveness of products and brands.

\subsection{Emotional processing}

A central brain region for emotional responses is the amygdala. In particular, it is involved in the processing of negative emotions and unknown stimuli, as well as in aversive responses to 
inequity (Rilling \& Sanfey, 2011). It is also known as a locus of aversive and fear memory (Maren \& Quirk, 2004). To a minor extent, it has equally been shown to process positive emotions, usually in relation to rewarding stimuli (Murray, 2007). Another key emotion-related region is the insula (or insular cortex). It plays a role in the processing of negative experiences such as the perception and expectation of risks, especially when making decisions for which a social or financial risk is expected (Preuschoff, Quartz, \& Bossaerts, 2008; Knutson \& Bossaerts, 2007). Likewise, the activation of the insula has been associated with anger and disgust in response to unfair economic situations (Sanfey et al., 2003). Additionally, as well as being involved in the evaluation process of stimuli (Section 2.1), the aforementioned OFC plays a role in experiencing and anticipating the emotion of regret when outcomes differ from expectations (Coricelli et al., 2005).

Finally, it is worth mentioning another area involved in emotional processing, the cingulate cortex, which includes the cingulate gyrus. Studies indeed suggest that the anterior cingulate evaluates emotional and motivational information and integrates it in the decision-making process (Bush, Luu, \& Posner, 2000). Moreover, the anterior cingulate has been associated with the experience of an internal conflict between alternative options, its activation possibly being due to a conflict between cognitive and emotional motivations (Sanfey et al., 2003). The role of emotions in decision-making has been further explained through neurological and cognitive frameworks such as the somatic marker the- ory (Reimann \& Bechara, 2010). Overall, the study of these brain mechanisms is likely to be central in consumer neuroscience due to the importance of the emotional component of purchase decisions in traditional consumer research (Bagozzi, Gopinath, \& Nyer, 1999). However, this will need to account for the complexity of the interconnected cerebral networks involved in emotions as there is not a single brain region responsible for emotional processes and no single brain region is activated in relation to one particular type of emotions (Phan, Wager, Taylor, \& Liberzon, 2002).

\subsection{Attention and memory}

The brain mechanisms involved in attention and visual processing could also be of interest to consumer research since advertising, logos and product designs all possess an important aesthetic component (e.g. shapes, colours) that is processed by the brain in the form of a visual stimulus. The aforementioned prefrontal cortex is responsible for directing and focusing attention and has been shown to connect with the neurons in charge of processing visual stimuli in the vision centre of the brain, called the occipital lobe (Armstrong, Fitzgerald, \& Moore, 2006). Similarly, the study of memory-related mental pro- cesses might provide useful findings 
Solnais, C., Andreu-Perez, J., Sánchez-Fernández, J., \& Andréu-Abela, J. (2013). The contribution of neuroscience to consumer research: A conceptual framework and empirical review. Journal of Economic Psychology, 36, 68-81.

in relation to variables influencing consumer behaviour such as product experience, brand awareness and advertising recall. Most importantly, the hippocampus, located in the temporal lobe, plays a major role in the formation of different forms of memory and is a central region for memory processing and consolidation (McGaugh, 2000), thus involved in long-term memory. In particular, it is key to the acquisition and recall of declarative memory (Eichenbaum, 2000). Additionally, the amygdala, situated next to the hippocampus to which it is closely related, plays an important role as a modulator of the memory system, particularly in the consolidation of memory (McGaugh, 2000).

Table 1. Summary of the main brain areas of interest to consumer neuroscience

\begin{tabular}{|c|c|c|}
\hline Brain area & Key functions of interest & References \\
\hline Amygdala & $\begin{array}{l}\text { Processing of emotions, particularly negative emotions; } \\
\text { aversive responses to inequity } \\
\text { Modulator of the memory system }\end{array}$ & $\begin{array}{l}\text { Rilling \& Sanfey (2011) } \\
\text { McGaugh (2000) }\end{array}$ \\
\hline $\begin{array}{l}\text { Anterior } \\
\text { cingulate }\end{array}$ & $\begin{array}{l}\text { Integration of emotional and motivational information in } \\
\text { the decision-making process } \\
\text { Internal conflict between alternative options }\end{array}$ & $\begin{array}{l}\text { Bush et al. (2000) } \\
\text { Sanfey et al. (2003) }\end{array}$ \\
\hline DLPFC & $\begin{array}{l}\text { Cognitive control, including over impulses towards } \\
\text { social norm compliance }\end{array}$ & Rilling \& Sanfey (2011) \\
\hline Hippocampus & $\begin{array}{l}\text { Formation and consolidation of memory (long-term } \\
\text { memory) } \\
\text { Acquisition and recall of declarative memory }\end{array}$ & $\begin{array}{l}\text { McGaugh (2000) } \\
\text { Eichenbaum (2000) }\end{array}$ \\
\hline Insula & $\begin{array}{l}\text { Perception and expectation of risks (e.g. financial and } \\
\text { social risks) } \\
\text { Anger and disgust against unfair economic situations }\end{array}$ & $\begin{array}{l}\text { Knutson \& Bossaerts } \\
(2007) ; \\
\text { Sanfey et al. (2003) }\end{array}$ \\
\hline Occipital lobe & Processing of visual stimuli & Armstrong et al. (2006) \\
\hline OFC & $\begin{array}{l}\text { Evaluation of the capacity of outcomes to satisfy one's } \\
\text { needs } \\
\text { Experience and anticipation of the emotion of regret } \\
\text { when outcomes differ from expectations }\end{array}$ & $\begin{array}{l}\text { Wallis (2007) } \\
\text { Coricelli et al. (2005) }\end{array}$ \\
\hline Striatum & Evaluation of actual rewards with respect to expectations & $\begin{array}{l}\text { Knutson } \quad \& \quad \text { Wimmer } \\
(2007)\end{array}$ \\
\hline VLPFC & $\begin{array}{l}\text { Representation of the threat of punishment for non- } \\
\text { compliance with social norms }\end{array}$ & Rilling \& Sanfey (2011) \\
\hline VMPFC & $\begin{array}{l}\text { Processing of different alternatives and their perceived } \\
\text { value }\end{array}$ & Daw et al. (2006) \\
\hline
\end{tabular}

Source: prepared by the authors. 


\section{Methodology}

\subsection{The tools of neuroscience}

In this section we review the three main neuroimaging techniques of consumer neuroscience as we will be referring to them throughout the article. Functional magnetic resonance imaging (fMRI) has developed as the most frequently applied to economic subjects in general (Kable, 2011). It consists in detecting and visualising, by means of an MRI scanner, the regional changes in the level of blood oxygenation in the brain (called the BOLD signal) produced by neural activity (see Reimann et al. (2011) for a complete methodological background). Other commonly used neuroimaging techniques are electroencephalography (EEG) and magnetoencephalography (MEG), which both measure brain activity at the scalp level, by means of electrodes and sensitive detectors, respectively. These three different technologies present different pros and cons (see Table 2), which must be assessed depending on the research purpose. While fMRI will better respond to the "where" question (i.e. the precise identification of the specific areas activated in response to marketing stimuli), the "when" question (i.e. the moment-by-moment tracking of brief neural activity changes as a stimulus evolves through time) will be better answered with EEG or MEG.

Table 2. Overview of the three neuroimaging techniques of interest.

\begin{tabular}{|c|c|c|c|c|}
\hline Technique & $\begin{array}{l}\text { How brain activity } \\
\text { is measured }\end{array}$ & Technology & Advantages & Limitations \\
\hline $\begin{array}{l}\text { Functional } \\
\text { magnetic } \\
\text { resonance } \\
\text { imaging }\end{array}$ & $\begin{array}{l}\text { Detecting the } \\
\text { changes in the } \\
\text { oxygenation level } \\
\text { of the blood. }\end{array}$ & $\begin{array}{l}\text { MRI scanner } \\
\text { inside which the } \\
\text { subject lies } \\
\text { during the time } \\
\text { of the } \\
\text { experiment. }\end{array}$ & $\begin{array}{l}\text { High spatial resolution } \\
(3 \mathrm{~mm}) \\
\text { Measurements cover } \\
\text { most brain regions, } \\
\text { including deeper ones. }\end{array}$ & $\begin{array}{l}\text { Relatively low } \\
\text { temporal } \\
\text { resolution (1-3 } \\
\text { seconds) } \\
\text { High costs. }\end{array}$ \\
\hline $\begin{array}{l}\text { Electro- } \\
\text { encephalo } \\
\text { graphy }\end{array}$ & $\begin{array}{l}\text { Detecting the } \\
\text { changes in the } \\
\text { electric current in } \\
\text { the form of brain } \\
\text { waves. }\end{array}$ & $\begin{array}{l}\text { Electrodes spread } \\
\text { on the subject's } \\
\text { head } \\
\text { (commonly } 64 \\
\text { sensors). }\end{array}$ & $\begin{array}{l}\text { High temporal resolution } \\
\text { (in milliseconds) for } \\
\text { the detection of brief } \\
\text { changes in brain } \\
\text { activity } \\
\text { Relatively low costs. }\end{array}$ & $\begin{array}{l}\text { Low spatial } \\
\text { resolution } \\
\text { (around } 1 \mathrm{~cm} \text {, } \\
\text { depending on } \\
\text { the number of } \\
\text { electrodes) }\end{array}$ \\
\hline $\begin{array}{l}\text { Magneto- } \\
\text { encephalo } \\
\text { graphy }\end{array}$ & $\begin{array}{l}\text { Detecting the } \\
\text { changes in the } \\
\text { magnetic field. }\end{array}$ & $\begin{array}{l}\text { Very sensitive } \\
\text { detectors set on } \\
\text { a helmet placed } \\
\text { on the subject's } \\
\text { head (more than } \\
100 \text { up to } 300 \\
\text { detectors). }\end{array}$ & $\begin{array}{l}\text { High temporal } \\
\text { resolution, comparable } \\
\text { to EEG. }\end{array}$ & $\begin{array}{l}\text { Low spatial } \\
\text { resolution, } \\
\text { although better } \\
\text { than EEG } \\
\text { Higher costs than } \\
\text { EEG. }\end{array}$ \\
\hline
\end{tabular}

Source: Prepared by the authors based on Kable (2011), Reimann et al. (2011), Senior et al. (2007). 


\subsection{Present research}

For the present research, we draw from a comprehensive selection of modern neuroeconomic studies applied to market- ing stimuli, spanning from 2001 to 2012. This time scope allowed accounting for the early applications of advanced neuro- imaging techniques that led to the birth of consumer neuroscience. We focused the review on the three main neuroimaging techniques, fMRI, EEG and MEG, provided that they were applied to the study of the brain's regional activity or hemispheric asymmetry. This criterion excluded just a few isolated studies while facilitating the comparisons between findings and ensuring a higher consistency of analysis. Since different methods and significance criteria were used in the statistical tests, each set of results was accepted according to the studies' own criteria and integrated as such in the review. Additionally, we chose to include a lesion study due to the high relevance of its findings within our empirical review. Finally, we retained only Englishlanguage articles from peer-reviewed journals indexed in the large databases of Proquest and Scopus.

Altogether, these criteria resulted in the collection of 34 studies, as summarised in Table 3. The recent interest in applying neuroscience techniques to the study of consumer psychology and behaviour is a multi-disciplinary phenomenon among the academic sphere. The studies are indeed being published not only in neuroscience journals but also in interdisciplinary journals such as the Journal of Economic Psychology, as well as in marketing journals. Despite this emergent interest, the majority of studies have been published by neuroscience journals, suggesting that neuroscience is still leading the application of its own methods to consumer studies while consumer research has remained reluctant to open to neuroscience.

Regarding methodological aspects, almost $70 \%$ of neuroimaging studies applied the most recent technique, that is, fMRI, while about one-fourth used EEG and only $6 \%$ opted for MEG. In particular, EEG and MEG were preferred as a better alter- native when high temporal resolution was required for studying the processing of TV advertisements moment by moment. However, it is worth noting that none of the studies combined different neuroimaging techniques despite the recommendations made in the literature (e.g. Kable, 2011; Senior, Smyth, Cooke, Shaw, \& Peel, 2007) and only two studies (Ohme, Rey- kowska, Wiener, \& Choromanska, 2009; Vecchiato et al., 2010) combined the selected neuroimaging technique with other psychophysiological measures (electromyography (EMG), galvanic skin response (GSR) and heart rate). Excluding the lesion study, the total number of subjects who processed the designed marketing stimuli during the neuroimaging experiments was 24 in average, although the median was 18 with a minimum of 10 , which reflects the exploratory nature of many consumer neuroscience studies. 
Solnais, C., Andreu-Perez, J., Sánchez-Fernández, J., \& Andréu-Abela, J. (2013). The contribution of neuroscience to consumer research: A conceptual framework and empirical review. Journal of Economic Psychology, 36, 68-81.

Table 3. Overview of the sample of studies

\begin{tabular}{|c|c|c|c|c|}
\hline Study & Category of journal & $\begin{array}{l}\text { Psychophysio- } \\
\text { logical } \\
\text { technique(s) }\end{array}$ & $\begin{array}{l}\text { Total \# } \\
\text { subjects }^{\mathrm{a}}\end{array}$ & $\begin{array}{l}\text { Main marketing } \\
\text { stimuli of } \\
\text { interest }\end{array}$ \\
\hline $\begin{array}{l}\text { Ambler, Braeutigam, } \\
\text { Stins, Rose, \& Swithenby, } \\
2004\end{array}$ & $\begin{array}{l}\text { Psychology \& } \\
\text { Marketing }\end{array}$ & MEG & 18 & Brands \\
\hline Astolfi et al., 2008 & $\begin{array}{l}\text { Biomedical } \\
\text { engineering }\end{array}$ & EEG & 10 & Advertising \\
\hline $\begin{array}{l}\text { Braeutigam, Rose, } \\
\text { Swithenby, \& Ambler, } \\
2004\end{array}$ & Neuroscience & MEG & 16 & Brands \\
\hline $\begin{array}{l}\text { Cook, Warren, Pajot, } \\
\text { Schairer, \& Leuchter, } \\
2011\end{array}$ & $\begin{array}{l}\text { Psychology, } \\
\text { Neuroscience \& } \\
\text { Economics }\end{array}$ & EEG & 24 & Advertising \\
\hline Deppe et al., 2007 & Neuroscience & fMRI & 21 & $\begin{array}{l}\text { Brands \& } \\
\text { Advertising }\end{array}$ \\
\hline $\begin{array}{l}\text { Deppe, Schwindt, Krämer, } \\
\text { et al., } 2005\end{array}$ & Neuroscience & fMRI & 21 & Brands \\
\hline $\begin{array}{l}\text { Deppe, Schwindt, Kugel, } \\
\text { Plassmann, \& Kenning, } \\
2005\end{array}$ & Neuroscience & fMRI & 22 & Brands \\
\hline Erk et al., 2002 & Neuroscience & fMRI & 12 & Products \\
\hline $\begin{array}{l}\text { Klucharev, Smidts, \& } \\
\text { Fernández, } 2008\end{array}$ & Neuroscience & fMRI & 24 & Advertising \\
\hline $\begin{array}{l}\text { Knutson, Rick, Wimmer, } \\
\text { Prelec, \& Loewenstein, } \\
2007\end{array}$ & Neuroscience & fMRI & 26 & Price \\
\hline Koenigs \& Tranel, 2008 & Neuroscience & Lesion study & 44 & Brands \\
\hline $\begin{array}{l}\text { Levy, Lazzaro, Rutledge, } \\
\text { \& Glimcher, } 2011\end{array}$ & Neuroscience & fMRI & 12 & Products \\
\hline McClure et al., 2004 & Neuroscience & fMRI & 67 & Brands \\
\hline Morris et al., 2009 & Neuroscience & fMRI & 12 & Advertising \\
\hline Ohme et al., 2009 & $\begin{array}{l}\text { Psychology, } \\
\text { Neuroscience \& } \\
\text { Economics }\end{array}$ & $\begin{array}{l}\text { EEG } \\
\text { EMG, GSR }\end{array}$ & 45 & Advertising \\
\hline $\begin{array}{l}\text { Ohme, Reykowska, } \\
\text { Wiener, \& Choromanska, } \\
2010\end{array}$ & $\begin{array}{l}\text { Psychology \& } \\
\text { Economics }\end{array}$ & EEG & 45 & Advertising \\
\hline Paulus \& Frank, 2003 & Neuroscience & fMRI & 15 & Brands \\
\hline $\begin{array}{l}\text { Plassmann, Kenning, } \\
\text { Deppe, Kugel, \& } \\
\text { Schwindt, } 2008\end{array}$ & Marketing & fMRI & 15 & Brands \\
\hline Plassmann, O'Doherty, \& & Neuroscience & fMRI & 20 & Products \\
\hline
\end{tabular}


Solnais, C., Andreu-Perez, J., Sánchez-Fernández, J., \& Andréu-Abela, J. (2013). The contribution of neuroscience to consumer research: A conceptual framework and empirical review. Journal of Economic Psychology, 36, 68-81.

Rangel, 2007

\begin{tabular}{|c|c|c|c|c|}
\hline $\begin{array}{l}\text { Plassmann, O'Doherty, } \\
\text { Shiv, \& Rangel, } 2008\end{array}$ & General & fMRI & 19 & Price \\
\hline $\begin{array}{l}\text { Raab, Elger, Neuner, \& } \\
\text { Weber, } 2011\end{array}$ & Marketing & fMRI & 49 & Price \\
\hline $\begin{array}{l}\text { Reimann, Castaño, } \\
\text { Zaichkowsky, \& Bechara, } \\
2012\end{array}$ & Marketing & fMRI & 17 & Brands \\
\hline $\begin{array}{l}\text { Reimann, Zaichkowsky, } \\
\text { Neuhaus, Bender, \& } \\
\text { Weber, } 2010\end{array}$ & $\begin{array}{l}\text { Psychology \& } \\
\text { Marketing }\end{array}$ & fMRI & 17 & Packaging \\
\hline $\begin{array}{l}\text { Rossiter, Silberstein, } \\
\text { Harris, \& Nield, } 2001\end{array}$ & Marketing & EEG & 35 & Advertising \\
\hline $\begin{array}{l}\text { Santos, Seixas, Brandão, } \\
\text { \& Moutinho, } 2012\end{array}$ & Marketing & fMRI & 12 & Brands \\
\hline Schaefer \& Rotte, 2007a & Neuroscience & fMRI & 14 & Brands \\
\hline Schaefer \& Rotte, 2007b & Neuroscience & fMRI & 14 & Brands \\
\hline $\begin{array}{l}\text { Schaefer, Berens, Heinze, } \\
\text { \& Rotte, } 2006\end{array}$ & Neuroscience & fMRI & 13 & Brands \\
\hline Stallen et al., 2010 & $\begin{array}{l}\text { Psychology \& } \\
\text { Economics }\end{array}$ & fMRI & 23 & Advertising \\
\hline $\begin{array}{l}\text { Stoll, Baecke, \& Kenning, } \\
2008\end{array}$ & Marketing & fMRI & 11 & Packaging \\
\hline \multirow[t]{2}{*}{ Vecchiato et al., 2010} & Neuroscience & EEG & 15 & Advertising \\
\hline & & \multicolumn{2}{|c|}{ GSR, Heart Rate } & \\
\hline Vecchiato et al., 2011 & $\begin{array}{l}\text { Biomedical } \\
\text { engineering }\end{array}$ & EEG & 11 & Advertising \\
\hline $\begin{array}{l}\text { Yoon, Gutchess, Feinberg, } \\
\& \text { Polk, } 2006\end{array}$ & Marketing & fMRI & 19 & Brands \\
\hline Young, 2002 & Marketing & EEG & 100 & Advertising \\
\hline
\end{tabular}

a These figures include all those groups of subjects whose brain activity was measured while they were exposed to the designed marketing stimuli. However, all other participants used for non-neuroimaging data are excluded. In the case of the lesion study, the displayed figure includes the patient group as well as the two comparison groups.

Source: prepared by the authors.

\section{Semantic cluster analysis}

In order to define the frontiers of consumer neuroscience, we carried out a semantic cluster analysis prior to a detailed empirical review. Semantic clustering is a technique of information 
retrieval that aims at automatically finding lemmas (also commonly described as discussion topics) from a text corpus (Berry, 2003). The degree of resemblance between word meanings is formalised through metrics called similarity measures (Huang, 2008), which in turn can be weighted through lexical databases (Miller, 1995). The computation of these similarity measures allows groups to be formed, where groups represent the most prominent lemmas of a scientific discussion. The strength of these lemmas with respect to the context can also be measured using their respective term frequency within the analysed text sources.

For the present analysis, we used Leximancer text-mining software, which applies artificial learning algorithms to automatically generate concept maps based on word frequency and cooccurrence. This was evaluated as a valid and reliable con- tent analysis method (Smith \& Humphreys, 2006). For this analysis, we collected the 34 abstracts from the selected studies, on the basis that abstracts synthesise the core issues of a study with a high lexical density. We then created semantic maps in order to obtain a conceptual overview of the field of consumer neuroscience. In doing so, we made appropriate merges be- tween word variants and synonym terms, and excluded general terms such as research, study and subjects since they did not provide additional information to the analysis.

Fig. 1 displays the resulting concept map. It sheds light on 20 terms identified as the key concepts from the sample of abstracts. Each concept is written in lower case letters in Fig. 1 and localised on the map with a point, hence 20 concept points. The size of each concept point indicates the connectedness of the concept to other concepts, which is determined by its summed co-occurrence count with all other concepts. A strong relationship between concepts is shown by their close position on the map; this is based on their tendency to appear in similar contexts within the source text. The resulting groups or clusters of semantically related concepts are represented by the nine circles along with a theme name (written in upper case).

This result highlights the prominence of the activity theme, as it presents the highest coverage across the data with a connectivity of $100 \%$ with all the available concepts. It encompasses the concepts of activity, cortex and prefrontal, with activity standing out as a central concept within the whole network and the first ranked concept in terms of frequency. This cluster is closely related to the one identified as brain, which includes the concept of stimuli. Altogether, this confirms the essential focus of consumer neuroscience studies on examining the activity of the brain during the observation of a given stimulus, with a particular concentration of today's empirical evidence on the prefrontal cortex activity (we discuss the findings about this region in Section 5).

The other two themes that relate to activity, i.e. fMRI and difference, further inform about the methodological aspects of existing studies. Given the concepts it contains, the first one 
confirms the popularity of fMRI within the field of consumer neuroscience as the preferred imaging technique to measure the neural effect of the stimulus of interest. The second one refers to the method used by studies to evaluate the significance of this effect; it consists in identifying differences in the brain's response to the information received from the stimulus compared with a control task or group.

The theme identified as regions contains the concepts of regions, associated and results, with the latter being closely related to suggest. This highlights the way conclusions are drawn from previous neuroscientific evidence about the brain region of interest being associated with a given cognitive or emotional function. Such inferences leading to the identification of a certain mental process based on the activation of a particular brain region follow a reasoning that is opposite to the one of neuroscience, which is consequently known as reverse inference (Poldrack, 2006). This can result in over-simplifications since it assumes that the activation of a given brain region is associated with only one particular psychological process.

Finally, the concepts of product, brand and commercials stand out as the three lowest ranked clusters and the least related to the central concepts given their position on the edges of the map. The semantic networks of the map connect all three to the concepts of activity or brain. In fact, the visualisation of the use of the three terms within the sample of abstracts shows that they are mostly mentioned as part of the description of the experimental design of the studies. Products, brands and TV advertisements are indeed primarily referred to as the stimuli used to study patterns of regional brain activation. Overall, this result suggests that current studies have focused on the neural mechanisms underlying the processing of marketing stimuli, with a lack of integration with economic and marketing theories. In parallel, it is interesting to note that the word consumer does not stand out from the sample of abstracts as a theme name nor does it appear as a concept. Again, this illustrates the prominence of the neuroscientific foundations of the field compared with a so-far timid influence from the consumer research discipline. It would be interesting to study the evolution of the themes and boundaries of consumer neuroscience in the future so as to monitor how methods will be improved and whether a progressive integration of consumer behaviour theories will be achieved.

Fig. 1. Semantic map of the concepts and themes of consumer neuroscience 


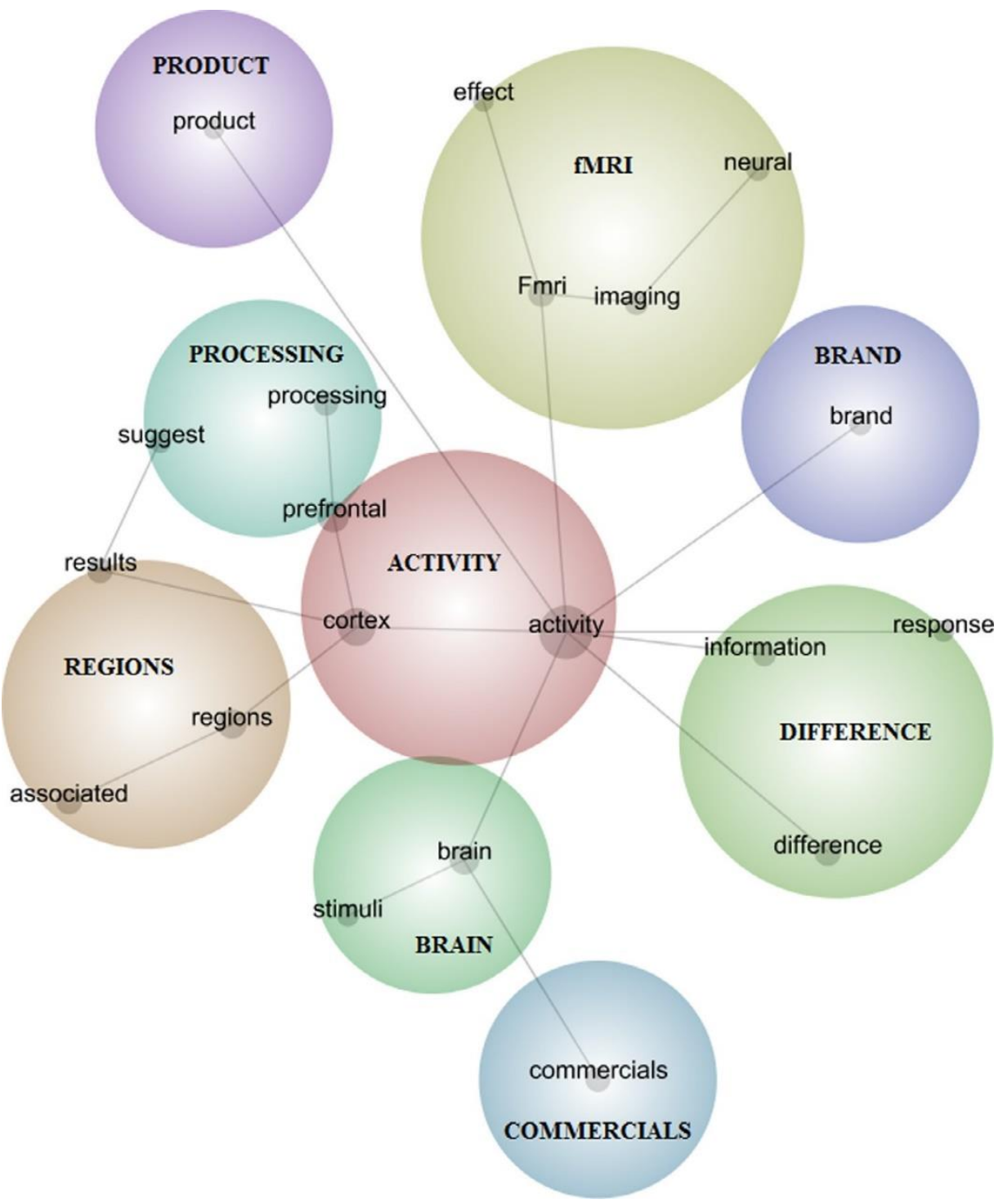

Source: prepared by the authors.

\section{Empirical review}

After having adopted a broad vision over the field of consumer neuroscience, we will now focus on analysing the actual contribution from current studies. While it would be too hasty for a definite framework to be set, we argue that a classification of findings from consumer neuroscience that is specific to the field is essential at this point. This will not only clarify the current state of empirical evidence by helping to relate results between studies, but also allow drawing more precise boundaries of the scope of consumer neuroscience. In this aim, a novel 
approach is proposed for the organisation of consumer neuroscience findings in order to integrate both neuroscientific and consumer orientations of the field.

Following both orientations, we structured our empirical review around four core categories of findings based on our col- lection of studies: (a) consumer decision-making and the formation of consumer preferences, (b) the engagement of the brain's reward system by marketing, (c) consumers' motivational and emotional responses, and (d) the neural foundations of consumers' attention and memory. The aim of this categorisation is indeed to be able to discuss and compare related findings between studies with respect to their contribution to each of these four topics. For example, the main findings of interest from Reimann, Castaño, Zaichkowsky, and Bechara (2012), Erk et al. (2002), Morris et al. (2009) and Rossiter, Silberstein, Harris, and Nield (2001) are explained in our empirical review within the first, second, third and fourth categories, respectively. Consequently, each category encompasses the diverse designs that might be employed to study one particular question. In other words, it includes all the variety of marketing stimuli that were empirically tested such as packaging designs, emotional advertising contents and brand logos. Thus, each type of marketing stimuli (advertising, price, product, etc.) might be designed and studied in a way that contributes to enhance our knowledge within each of the four questions (Fig. 2).

Fig. 2. Proposed framework for assessing the contribution of neuroscience to consumer research with respect to four core questions

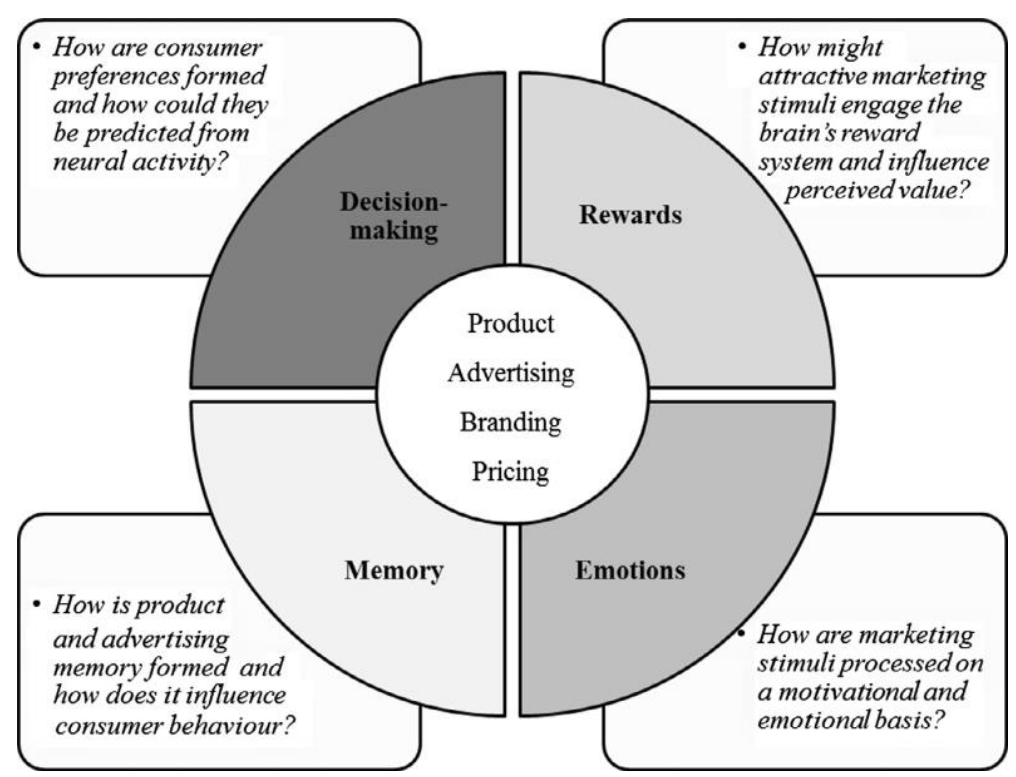

Source: prepared by the authors 


\subsection{Consumer decision-making and the formation of consumer preferences}

A growing number of studies are attempting to address the question of the formation of consumer preferences based on neural activity. The use of MEG during virtually simulated supermarket purchases has provided primary insights about a possibly differing neural pattern of decision-making depending on brand familiarity (Ambler, Braeutigam, Stins, Rose, \& Swithenby, 2004), gender and choice predictability, that is, the level of experience with a product (Braeutigam, Rose, Swithenby, \& Ambler, 2004). However, most of the research has concentrated on fMRI applications allowing for more precise brain localisation. In particular, the medial orbitofrontal cortex was associated with willingness-to-pay decisions during individual bids for highly familiar junk food products (Plassmann, O’Doherty, \& Rangel, 2007) while the VMPFC was shown to be activated during brand choices between two similar products (Deppe, Schwindt, Kugel, Plassmann, \& Kenning, 2005; Paulus \& Frank, 2003). A lesion study provided consistent findings about the role of the VMPFC in developing brand preferences manifested in biased taste judgments between Coca-Cola and Pepsi for all subjects but VMPFC patients (Koenigs \& Tranel, 2008). The combination of fMRI data with behavioural measures even suggests that consumer preferences might be predicted based on the VMPFC. Thus, the activity in the VMPFC during a blind test of cola drinks was found to correlate with taste preferences due to the evaluation of reward value by the VMPFC as part of its role in the decision-making process (McClure et al., 2004). Moreover, in an experiment where subjects were asked to either choose or reject each individually presented brand logo, the activation of the VMPFC in- creased prior to the subject's expressed choice in the case of novel brands versus familiar brands (Reimann et al., 2012). Such result might be explained by a stronger engagement in the decision-making process involved in consumers' assessment of the (perceived) value of products when faced with unknown brands.

To a minor extent, the activation of the MPFC has been interpreted as an indicator of a selfrelevant or self-centred type of information processing in the case of prestigious and culturally familiar brands (Schaefer, Berens, Heinze, \& Rotte, 2006; Schaefer \& Rotte, 2007b). Since luxury car brand logos were used and subjects were asked to imagine driving the car of the viewed brand, it was suggested that they might be experiencing feelings of proud and selfesteem in relation to the desire of possessing the cars of such brands. This self-relevant information might be integrated in the decision-making process and this way influence the formation of consumer preferences. Similarly, studies have explored the role of complementary areas in the integration of implicit or emotional information in the decision-making process, 
which includes information about intangible product attributes such as perceived brand image. Specifically, choices between two different brands of a similar product were found to activate the cingulate cortex (Deppe, Schwindt, Kugel, et al., 2005; Paulus \& Frank, 2003; Plassmann, Kenning, Deppe, Kugel, \& Schwindt, 2008) and the insula (Paulus \& Frank, 2003). Given the aforementioned functions of these areas, this would be consistent with the idea that the formation of consumer preferences does not solely rely on a rational evaluation of product attributes but also involves non-rational and emotional decision-making processes. In particular, the latter could play a role in the integration of emotions attached to favourite brands. Indeed, binary choices involving the subject's first-choice brand were associated with an increased activity in the cingulate cortex whereas the absence of prior preference led to a stronger use of the parietal and occipital cortices associated with working memory, reasoning and visual processing (Deppe, Schwindt, Kugel, et al., 2005). Likewise, the activation of the cingulate cortex was associated with the processing of implicit brand information such as the image or reputation of news magazine brands; this could be influencing the evaluation of the credibility of the news headlines (Deppe, Schwindt, Krämer, et al., 2005) and the perception of the advertisements contained in these news magazines (Deppe et al., 2007). However, on a related question about whether brands could even be processed in a similar way to persons, fMRI measures during semantic judgements showed that the processing of "brand personalities" activated object-processing regions, as a contrary to the processing of persons (Yoon, Gut- chess, Feinberg, \& Polk, 2006).

In summary, consumer neuroscience has started to provide converging evidence on the role of the VMPFC in consumer decision-making. Additionally, an increasing number of studies suggest a possible interaction of the PFC with the cingulate cortex to allow for the evaluation of implicit brand information within the decision-making process. A remaining challenge will be to further investigate the possibility to predict consumer preferences based on the VMPFC by addressing the problem of uncontrolled variables within the complex design of simulated purchase situations and other product judgement experiments.

\subsection{When marketing appeals to the reward system of consumers' brains}

Consumer neuroscience has started to examine the question of how the attractiveness of marketing stimuli might be inferred based on the regional activity within the brain's reward system. Thus, preferred consumer goods were associated with the activation of the striatum when viewed individually (Levy, Lazzaro, Rutledge, \& Glimcher, 2011), and more specifically in the nucleus accumbens (Knutson, Rick, Wimmer, Prelec, \& Loewenstein, 2007), thus 
suggesting that (subjectively) attractive products might work as rewarding stimuli within the brain. Additionally, the striatum was found to be activated during the mere visual processing of favourite brands of luxury sport cars as opposed to basic functional brands (Schaefer \& Rotte, 2007a). Likewise, using grey-scaled photographs without brand names, the visual processing of sport cars was associated with significantly higher activations of the striatum and the orbitofrontal cortex, compared with other categories of cars perceived as less attractive (Erk et al., 2002). Products symbolising wealth and social status could therefore influence the reward pathways of the brain (in the striatum) with this perception of rewarding outcomes being translated into the evaluation of a higher capacity to satisfy their needs (in the orbitofrontal cortex). Interestingly, a recent study compared regional brain activity between compulsive and non-compulsive buyers during purchase decisions and found a significantly higher activation of the nucleus accumbens within the striatum of compulsive buyers, therefore suggesting that compulsive shopping behaviour may result from a stronger engagement of the brain's reward system in response to marketing stimuli (Raab, Elger, Neuner, \& Weber, 2011).

Within the same topic of marketing appealing to the reward system, fewer studies have focused on product packaging as the stimulus of interest. Specifically, individually presented packages perceived as attractive or aesthetic were reported to activate regions related to reward processing when compared with unattractive or functional packages (Reimann, Zaich- kowsky, Neuhaus, Bender, \& Weber, 2010; Stoll, Baecke, \& Kenning, 2008). However, while the MPFC was activated in both experiments, the nucleus accumbens, which is more specifically known as part of the reward system, was reported to be activated in only one of the two studies (Reimann et al., 2010). This aspect deserves further applications in order to confirm the ability of product packaging to act as a rewarding stimulus within consumers' brains and this way influence shopping decisions.

Finally, consumer neuroscience has explored the reverse possibility of consumers perceiving and expecting the risk of a punishment or negative outcome (e.g. getting an unfair deal) in relation to the marketing stimuli being processed. Thus, in a ground-breaking fMRI study on purchase decisions for individually offered items, excessive prices led to the activation of the insula, explained by the perception of an unfair offer or a financial risk associated with the purchase of such products (Knutson et al., 2007). Interestingly though, higher prices were also found to increase activity in the medial orbitofrontal cortex during the tasting of wines and positively influence subjective evaluations of flavour pleasantness, even though two of the three wines were administered twice (Plassmann, O’Doherty, Shiv, \& Rangel, 2008). Therefore, premium prices may enhance perceived value and rewards within the assessment of certain types of products. 
Altogether, interesting findings have started to provide answers about the ability of marketing to engage the brain's reward system, particularly through the striatum. However, further evidence is needed to confirm whether attractive packaging and favourite brands could be reliably predicted based on a specific pattern of neural activation within the brain's reward system. In addition, future research could further investigate whether such findings will be limited to certain product categories such as luxury products, appetising junk foods and sweet drinks, as these have been the most commonly used in the experimental designs so far. In parallel, it would be interesting to explore the way effective advertisements might also engage the brain's reward system in a reward assessment process as a result of the perception of product benefits. This would indeed illustrate the capacity of effective advertisements to highlight rewarding outcomes from consumption and therefore influence consumer preferences.

\subsection{Consumers' motivational tendencies and emotional responses}

Another part of the evidence provided by consumer neuroscience can be gathered under the question of consumers' motivational and emotional responses to marketing stimuli. In particular, by monitoring the brain's hemispheric asymmetry, EEG has started eliciting distinct neural patterns associated with different levels of perceived pleasantness attached to advertising, where "pleasant" was defined as a degree of liking an advertisement. Thus, the advertisements perceived as the most pleasant (rated between 7 and 9 on a scale of $1-10,10$ being "highly pleasant") were associated with an asymmetrical increase in the neural activity of the left hemisphere whereas unpleasant advertisements were associated with a relatively greater activity increase in the right hemisphere (Vecchiato et al., 2011). In other words, according to the approach-avoidance model (Davidson, 2004) pleasant advertisements could be able trigger approach motivations towards products and brand messages through a greater engagement of the left hemisphere.

As an example of application, a recent study tested the audio-visual processing of three different TV advertisements for the same Sony advertising campaign. They found that one particular advertisement allowed generating a significantly greater activation in the left frontal hemisphere (Ohme, Reykowska, Wiener, \& Choromanska, 2010). This could potentially suggest the higher effectiveness of the design of this specific advertisement in generating approach reactions from the audience. However, no behavioural measures were used to verify the subjects' attitudes towards each advertisement and the brand. Taken together, it would be interesting to confirm these isolated findings in further brain asymmetry studies given the potential of such research to enhance our knowledge about the effects of advertising. 
To a minor extent, consumer neuroscience research has explored whether distinct neural patterns underlie the processing of rational versus non-rational advertising stimuli. Rational refers to the use of logical or factual information in the advertisement, as opposed to other persuasion techniques such as evocative images where the message is not consciously recognised. A recent EEG study using print advertising found that logical persuasion messages were associated with significantly higher levels of neural activity in the hippocampus, which could suggest a stronger acquisition of declarative memory (Cook, Warren, Pajot, Schairer, \& Leuchter, 2011). Nevertheless, these rational advertising contents were equally associated with significantly higher activations in the amygdala and anterior cingulate, which appears contradictory with the role of these areas in emotional processing. Therefore, although the findings suggest that rational and non-rational advertising stimuli might be processed differently by the brain, it is unclear whether each type of processing could occur in a well-identified set of brain regions. On a similar question, when focusing on the emotional processing of TV advertisements, significant differences were found in the activations of areas involved in emotional responses according to the pleasure versus arousal dimensions of emotions, particularly in the inferior frontal gyrus and middle temporal gyrus (Morris et al., 2009). Further research could build on this primary result so as to probe the hypothesis that the different dimensions of emotions relate to specific patterns of regional brain activations.

In summary, consumer neuroscience has provided relatively few answers to the question of consumers' motivational and emotional responses so far as there is still little evidence of the brain areas activated during the processing of non-rational advertising messages. A more frequent combination of neuroimaging data with behavioural measures will be important in future research. This should help to further investigate the role of specific brain activation patterns in relation to the constructs of consumers' motivations and emotions.

\subsection{The neural foundations of consumers' attention and memory}

The study of the neural foundations of consumers' attention and memory has been applied to a variety of questions and marketing stimuli. Specifically, attractive packages were associated with significant activations in brain regions involved in the processing of visual stimuli and attention (the occipital lobe and precuneus) compared with unattractive packages (Stoll et al., 2008). If confirmed in further research, this finding would suggest that better designed packaging may benefit from higher visual processing and attention, which could explain the capacity of attractive packaging to catch consumers' eyes and interest on supermarket shelves. 
As regards the processing of brands, familiar brands were shown to activate the hippocampus (McClure et al., 2004; San- tos, Seixas, Brandão, \& Moutinho, 2012; Schaefer \& Rotte, 2007b), which can be interpreted as the use of memory for consumers to recall their experience with the brand including advertising messages, product trials and peer recommendations. In particular, the hippocampus was significantly activated during taste judgement tasks between two cola drinks when the brand name was provided compared with a blind-test condition, while behavioural preferences were modified in favour of Coca-Cola (McClure et al., 2004). Such results could suggest that the memory of brand information and experience might be retrieved through the hippocampus and influence consumer preferences by generating a "brand bias' on the perception of tangible product attributes such as taste.

In parallel, a growing number of studies have focused on the question of the neural foundations of advertising memory by measuring brain activity during the audio-visual processing of TV advertisements. An early study explored the relation be- tween brain waves and the memorisation of specific advertising scenes (Young, 2002). In a similar vein, the fastest activations in the left frontal hemisphere were associated with the scenes that were best recognised 1 week later (Rossiter et al., 2001). Likewise, the cortical activity was significantly higher in the left frontal areas for the TV advertisements that were remembered after the experiment compared with the forgotten ones (Vecchiato et al., 2010).

Taken together, this primary evidence suggests that the extent to which an advertisement is recalled could depend on a relatively stronger engagement of the left frontal hemisphere. This might be explained by the role of the left frontal hemi- sphere in long-term memory processing from visual stimuli as proposed in Rossiter et al. (2001). According to Davidson's approachavoidance model, this enhanced capacity to memorise an advertising stimulus could alternatively be related to higher approach motivations towards the advertisement, by increasing subjects' openness and predisposition to remember it. Overall, further research using brain wave measures combined with traditional recall tests could better inform about the attention paid to specific advertising scenes and potentially lead to neuroimaging-based predictions of recall rates.

Complementary results were reported about the possible role of the prefrontal cortex and parietal areas in processing information from advertising contents and memorising advertisements by transferring sensory perceptions from short-term to long-term memory (Astolfi et al., 2008). In parallel, consumer neuroscience has started to study the effectiveness of specific persuasive advertising designs in enhancing product memory such as celebrity endorsements, which has long been investigated through traditional market research techniques (Petty \& Cacioppo, 1983). First exploratory findings were provided about the brain 
mechanisms that may underlie the processing of products when associated with the image of a celebrity, whether the latter is shown within the same picture (Stallen et al., 2010) or in a separate picture preceding the product (Klucharev, Smidts, \& Fernández, 2008). Specifically, the use of celebrities with perceived expertise was shown to significantly activate regions involved in memory formation within the temporal lobe including the hippocampus; these possibly superior memory effects appeared consistent with behavioural measures of product recognition (Klucharev et al., 2008). On a related question, a multi-method study highlighted the presence of significant differences in the psychophysiological responses to slightly differing TV advertising scenes, although the viewers could not consciously notice the difference (Ohme et al., 2009). If further confirmed, such results would appear consistent with the concept of subliminal advertising.

In summary, neuroscientific techniques have provided a growing number of findings in relation to the topic of consumers' memory. These mainly confirm the participation of the hippocampus and the left frontal hemisphere in the memorisation of various types of marketing stimuli. However, there has been a particularly high heterogeneity as regards the techniques and procedures used so far to address this question according to our sample of studies. Although this highlights the high interest in exploring many different aspects of the neural foundations of consumers' memory, further research is needed to confirm existing findings.

\section{Discussion}

The review of existing findings from consumer neuroscience provides a clarified empirical basis about the underlying neural processes of consumers' inner responses to marketing stimuli. There is growing, converging evidence about the role of the MPFC in the decision-making process involved in the formation of product and brand preferences. The cingulate cortex might influence this process through the integration of emotional and implicit brand information. Additionally, a consistent set of findings have started to explore the ability of marketing stimuli to engage the brain's reward system, particularly through the striatum. In parallel, it will be interesting to further investigate the role of the hippocampus and left frontal hemisphere in the memory of brand experience such as advertising messages.

However, the present research highlights important limitations to the contribution of neuroscientific techniques to consumer research. In particular, the high heterogeneity in the methods and experimental conditions used within the field of consumer neuroscience increases the difficulty to make generalisations that are meaningful to consumer research. In addition, methodological problems exist against a systematic identification of specific variables of 
consumer behaviour models solely based on neuroscientific experiments. This is not only due to the aforementioned issue of reverse inference from neuroimaging data but also to the difficulty to control for every single factor affecting subjects' neural activity. Altogether, these are major obstacles to making the necessary bridge between neuroimaging data and theories of economic psychology. This can explain the absence of new consumer behaviour models that integrate the findings from neuroimaging experiments and go beyond traditional "black box" models, hence a relatively limited application of these techniques to marketing so far. As a result, although consumer neuroscience has certainly enhanced our knowledge of the brain and neural mechanisms applied to the processing of marketing stimuli, little progress has been made towards the integration and verification of existing consumer behaviour theories.

\section{Conclusion}

To the knowledge of the authors, our paper provides the first comprehensive empirical review and classification attempt of the contribution of consumer neuroscience from a consumer behaviour research perspective. Our analysis builds on a review of the theoretical framework, which should support the further diffusion of the neuroscientific background among economic and marketing scholars. Additionally, the semantic cluster analysis contributes to defining the boundaries and methods of the growing field of consumer neuroscience. The empirical review provides a detailed evidence synthesis as well as key summary points of the current advances and limitations considering central concepts in relation to consumer behaviour such as decisionmaking, rewards, memory, motivations and emotions. This could serve for future research to complete or revise existing findings and evolve towards a more frequent use of deductive designs through the setting of hypotheses.

Regarding the limitations of our research, the results of the semantic cluster analysis about the current concepts and topics of consumer neuroscience depend on the quality of the abstracts used as our input data. In addition, only two databases served the collection of studies included in the empirical review. While this is somehow offset by the fact that ProQuest and Scopus are ones of the largest databases worldwide, it would be interesting to widen the scope of study to further databases in future research syntheses. Additionally, the fact that findings were extracted from studies with varying designs and methods should invite readers to consider the present results as preliminary, against the risk of premature conclusions about a definite functional specialisation of the brain in relation to the processing of marketing stimuli.

Future research could focus on improving and standardising the methods of the still-nascent field of consumer neuroscience, so that further comparisons and generalisations can be made 
across studies. Likewise, a more frequent verification of neuroimaging results through behavioural measures should support further connections with classical constructs of consumer research. In addition, the integration of neuroscience, economic psychology and consumer research within multidisciplinary teams will play an important role in blurring the frontiers between the interested disciplines, as already highlighted by several authors (Kenning et al., 2007; Senior et al., 2007). Most importantly, it appears from our review that fMRI and other modern neuroimaging techniques are unlikely to revolutionise the field of economic psychology and that they cannot replace traditional behavioural science methods and self-report measures. Overall, the authors believe that it is the joint use of different methods within consumer research that will be essential for a more precise and thorough under- standing of the different components of consumer behaviour.

\section{Acknowledgement}

The authors acknowledge the support of the ECO2012-39576 Project from the Spanish Government as well as the P10.SEJ.6768 Project from the Regional Government of Andalusia.

\section{References}

Addie, I. (2011). Is neuroscience facilitating a new era of the hidden persuader? International Journal of Market Research, 53(3), 303.

Ambler, T., Braeutigam, S., Stins, J., Rose, S., \& Swithenby, S. (2004). Salience and choice: Neural correlates of shopping decisions. Psychology and Marketing,

21(4), 247-261.

Armstrong, K. M., Fitzgerald, J. K., \& Moore, T. (2006). Changes in visual receptive fields with microstimulation of frontal cortex. Neuron, 50(5), 791-798.

Astolfi, L., De Vico Fallani, F., Cincotti, F., Mattia, D., Bianchi, L., Marciani, M. G., et al (2008). Neural basis for brain responses to TV commercials: A high- resolution EEG study. IEEE Transactions on Neural Systems and Rehabilitation Engineering, 16(6), 522-531.

Bagozzi, R. P., Gopinath, M., \& Nyer, P. U. (1999). The role of emotions in marketing. Journal of the Academy of Marketing Science, 27(2), 184-206. Berridge, K. C. (1996). Food reward: Brain substrates of wanting and liking. Neuroscience \& Biobehavioral Reviews, 20(1), 1-25. 
Berry, M. W. (2003). Survey of text mining I: Clustering, classification, and retrieval (Vol. 1). Springer.

Braeutigam, S., Rose, S. P. R., Swithenby, S. J., \& Ambler, T. (2004). The distributed neuronal systems supporting choice-making in real-life situations: Differences between men and women when choosing groceries detected using magnetoencephalography. European Journal of Neuroscience, 20(1),

293-302.

Bush, G., Luu, P., \& Posner, M. I. (2000). Cognitive and emotional influences in anterior cingulate cortex. Trends in Cognitive Sciences, 4(6), 215-222. Camerer, C. (2007). Neuroeconomics: Using neuroscience to make economic predictions. The Economic Journal, 117(519), C26-C42.

Camerer, C., Loewenstein, G., \& Prelec, D. (2005). Neuroeconomics: How neuroscience can inform economics. Journal of Economic Literature, 43(1), 9-64. Cook, I. A., Warren, C., Pajot, S. K., Schairer, D., \& Leuchter, A. F. (2011). Regional brain activation with advertising images. Journal of Neuroscience, Psychology, and Economics, 4(3), 147-160.

Coricelli, G., Critchley, H. D., Joffily, M., O’Doherty, J. P., Sirigu, A., \& Dolan, R. J. (2005). Regret and its avoidance: A neuroimaging study of choice behavior.

Nature Neuroscience, 8(9), 1255-1262.

Davidson, R. J. (2004). What does the prefrontal cortex "do"' in affect: Perspectives on frontal EEG asymmetry research. Biological Psychology, 67(1), 219-234. Daw, N. D., O’Doherty, J. P., Dayan, P., Seymour, B., \& Dolan, R. J. (2006). Cortical substrates for exploratory decisions in humans. Nature, 441(7095), 876-879. Deppe, M., Schwindt, W., Krämer, J., Kugel, H., Plassmann, H., Kenning, P., et al (2005). Evidence for a neural correlate of a framing effect: Bias-specific

activity in the ventromedial prefrontal cortex during credibility judgments. Brain Research Bulletin, 67(5), 413-421.

Deppe, M., Schwindt, W., Kugel, H., Plassmann, H., \& Kenning, P. (2005). Nonlinear responses within the medial prefrontal cortex reveal when specific implicit information influences economic decision making. Journal of Neuroimaging, 15(2), 171-182.

Deppe, M., Schwindt, W., Pieper, A., Kugel, H., Plassmann, H., Kenning, P., et al (2007). Anterior cingulate reflects susceptibility to framing during attractiveness evaluation. Neuroreport, 18(11), 1119-1123.

Eichenbaum, H. (2000). A cortical-hippocampal system for declarative memory. Nature Reviews Neuroscience, 1(1), 41-50. 
Solnais, C., Andreu-Perez, J., Sánchez-Fernández, J., \& Andréu-Abela, J. (2013). The contribution of neuroscience to consumer research: A conceptual framework and empirical review. Journal of Economic Psychology, 36, 68-81.

Elliott, R., Dolan, R. J., \& Frith, C. D. (2000). Dissociable functions in the medial and lateral orbitofrontal cortex: Evidence from human neuroimaging studies.

Cerebral Cortex, 10(3), 308-317.

Engel, J., Kollat, D., \& Blackwell, R. (1968). Consumer behavior. New York, USA: Holt, Rinehart and Winston, Inc.

Erk, S., Spitzer, M., Wunderlich, A. P., Galley, L., \& Walter, H. (2002). Cultural objects modulate reward circuitry. Neuroreport, 13(18), 2499-2503.

Fields, H. L., Hjelmstad, G. O., Margolis, E. B., \& Nicola, S. M. (2007). Ventral tegmental area neurons in learned appetitive behavior and positive reinforcement. Annual Review of Neuroscience, 30, 289-316.

Fliessbach, K., Weber, B., Trautner, P., Dohmen, T., Sunde, U., Elger, C. E., et al (2007). Social comparison affects reward-related brain activity in the human ventral striatum. Science, 318(5854), 1305-1308.

Fugate, D. L. (2007). Neuromarketing: A layman's look at neuroscience and its potential application to marketing practice. Journal of Consumer Marketing,

24(7), 385-394.

Gonzalez, C., Dana, J., Koshino, H., \& Just, M. (2005). The framing effect and risky decisions: Examining cognitive functions with fMRI. Journal of Economic

Psychology, 26(1), 1R20.

Hansen, F., Kenning, P., \& Plassmann, H. (2010). Contributions to decision neuroscience. Journal of Economic Psychology, 31(5), 764-766. Harmon-Jones, E. (2003). Clarifying the emotive functions of asymmetrical frontal cortical activity. Psychophysiology, 40(6), 838-848. Howard, J. A., \& Sheth, J. N. (1969). The theory of buyer behavior. New York, USA: John Willey \& Sons, Inc.

Huang, A. (2008). Similarity measures for text document clustering. In Proceedings of the sixth New Zealand computer science research student conference

(NZCSRSC2008), Christchurch, New Zealand.

Hubert, M. (2010). Does neuroeconomics give new impetus to economic and consumer research? Journal of Economic Psychology, 31(5), 812-817. Hubert, M., \& Kenning, P. (2008). A current overview of consumer neuroscience. Journal of Consumer Behaviour, 7(4-5), 272292.

Jamison, J., \& Wegener, J. (2010). Multiple selves in intertemporal choice. Journal of Economic Psychology, 31(5), 832-839.

Kable, J. W. (2011). The cognitive neuroscience toolkit for the neuroeconomist: A functional overview. Journal of Neuroscience, Psychology, and Economics, 
Solnais, C., Andreu-Perez, J., Sánchez-Fernández, J., \& Andréu-Abela, J. (2013). The contribution of neuroscience to consumer research: A conceptual framework and empirical review. Journal of Economic Psychology, 36, 68-81.

4(2), 63-84.

Kenning, P., Plassmann, H., \& Ahlert, D. (2007). Applications of functional magnetic resonance imaging for market research. Qualitative Market Research: An

International Journal, 10(2), 135-152.

Klucharev, V., Smidts, A., \& Fernández, G. (2008). Brain mechanisms of persuasion: How 'expert power' modulates memory and attitudes. Social Cognitive and Affective Neuroscience, 3(4), 353-366.

Knutson, B., Adams, C. M., Fong, G. W., \& Hommer, D. (2001). Anticipation of increasing monetary reward selectively recruits nucleus accumbens. The Journal of Neuroscience, 21(16), $1-5$.

Knutson, B., \& Bossaerts, P. (2007). Neural antecedents of financial decisions. The Journal of Neuroscience, 27(31), 8174-8177. Knutson, B., Rick, S., Wimmer, G. E., Prelec, D., \& Loewenstein, G. (2007). Neural predictors of purchases. Neuron, 53(1), 147-156.

Knutson, B., \& Wimmer, G. E. (2007). Splitting the difference: How does the brain code reward episodes? Annals of the New York Academy of Sciences, 1104,

$54-69$.

Koenigs, M., \& Tranel, D. (2008). Prefrontal cortex damage abolishes brand-cued changes in cola preference. Social Cognitive and Affective Neuroscience, 3(1),

$1-6$.

Krugman, H. E. (1971). Brain wave measures of media involvement. Journal of Advertising Research, 11(1), 3-9.

Lee, N., Broderick, A. J., \& Chamberlain, L. (2007). What is 'neuromarketing'? A discussion and agenda for future research. Cognitive Neuroscience: Contributions from Psychophysiology, 63(2), 199-204.

Levy, I., Lazzaro, S. C., Rutledge, R. B., \& Glimcher, P. W. (2011). Choice from non-choice: Predicting consumer preferences from blood oxygenation level-

dependent signals obtained during passive viewing. The Journal of Neuroscience, 31(1), 118125.

Ma, Q., Wang, X., Shu, L., \& Dai, S. (2008). P300 and categorization in brand extension. Neuroscience Letters, 431(1), 57-61. Maren, S., \& Quirk, G. J. (2004). Neuronal signalling of fear memory. Nature Reviews Neuroscience, 5(11), 844-852.

McClure, S. M., Li, J., Tomlin, D., Cypert, K. S., Montague, L. M., \& Montague, P. R. (2004). Neural correlates of behavioral preference for culturally familiar drinks. Neuron, 44(2), 379387.

McGaugh, J. L. (2000). Memory - A century of consolidation. Science, 287(5451), 248-251. 
Solnais, C., Andreu-Perez, J., Sánchez-Fernández, J., \& Andréu-Abela, J. (2013). The contribution of neuroscience to consumer research: A conceptual framework and empirical review. Journal of Economic Psychology, 36, 68-81.

Miller, G. A. (1995). WordNet: A lexical database for English. Communications of the ACM, 38(11), 39-41.

Moreira, B., Matsushita, R., \& Da Silva, S. (2010). Risk seeking behavior of preschool children in a gambling task. Journal of Economic Psychology, 31(5),

794-801.

Morris, J. D., Klahr, N. J., Shen, F., Villegas, J., Wright, P., He, G., et al (2009). Mapping a multidimensional emotion in response to television commercials.

Human Brain Mapping, 30(3), 789-796.

Murray, E. A. (2007). The amygdala, reward and emotion. Trends in Cognitive Sciences, 11(11), 489-497.

Nicosia, F. M. (1966). Consumer decision process: Marketing and advertising implications. NJ, USA: Prentice Hall, Englewood Cliffs. Nighswonger, N. J., \& Martin, C. R. Jr., (1981). On using voice analysis in marketing research. Journal of Marketing Research, 350-355.

Ohme, R., Reykowska, D., Wiener, D., \& Choromanska, A. (2009). Analysis of neurophysiological reactions to advertising stimuli by means of EEG and galvanic skin response measures. Journal of Neuroscience, Psychology, and Economics, 2(1), $21-31$.

Ohme, R., Reykowska, D., Wiener, D., \& Choromanska, A. (2010). Application of frontal EEG asymmetry to advertising research. Journal of Economic

Psychology, 31(5), 785-793.

Paulus, M. P., \& Frank, L. R. (2003). Ventromedial prefrontal cortex activation is critical for preference judgments. Neuroreport, 14(10), 1311-1315.

Petty, R. E., \& Cacioppo, J. T. (1983). The role of bodily responses in attitude measurement and change. In Social psychophysiology: A sourcebook. New York: Guilford Press.

Phan, K. L., Wager, T., Taylor, S. F., \& Liberzon, I. (2002). Functional neuroanatomy of emotion: A meta-analysis of emotion activation studies in PET and fMRI.

NeuroImage, 16(2), 331-348.

Plassmann, H., Kenning, P., Deppe, M., Kugel, H., \& Schwindt, W. (2008). How choice ambiguity modulates activity in brain areas representing brand preference: Evidence from consumer neuroscience. Journal of Consumer Behaviour, 7(4-5), 360-367.

Plassmann, H., O’Doherty, J., \& Rangel, A. (2007). Orbitofrontal cortex encodes willingness to pay in everyday economic transactions. The Journal of Neuroscience, 27(37), 9984-9988. 
Solnais, C., Andreu-Perez, J., Sánchez-Fernández, J., \& Andréu-Abela, J. (2013). The contribution of neuroscience to consumer research: A conceptual framework and empirical review. Journal of Economic Psychology, 36, 68-81.

Plassmann, H., O’Doherty, J., Shiv, B., \& Rangel, A. (2008). Marketing actions can modulate neural representations of experienced pleasantness. Proceedings of the National Academy of Sciences, 105(3), 1050.

Poldrack, R. A. (2006). Can cognitive processes be inferred from neuroimaging data? Trends in Cognitive Sciences, 10(2), 59-63.

Preuschoff, K., Quartz, S. R., \& Bossaerts, P. (2008). Human insula activation reflects risk prediction errors as well as risk. The Journal of Neuroscience, 28(11),

$2745-2752$.

Raab, G., Elger, C., Neuner, M., \& Weber, B. (2011). A neurological study of compulsive buying behaviour. Journal of Consumer Policy, 34(4), 401-413. Ramsøy, T. Z., \& Skov, M. (2010). How genes make up your mind: Individual biological differences and value-based decisions. Journal of Economic Psychology,

31(5), 818-831.

Reimann, M., \& Bechara, A. (2010). The somatic marker framework as a neurological theory of decision-making: Review, conceptual comparisons, and future neuroeconomics research. Journal of Economic Psychology, 31(5), 767-776.

Reimann, M., Castaño, R., Zaichkowsky, J., \& Bechara, A. (2012). Novel versus familiar brands: An analysis of neurophysiology, response latency, and choice.

Marketing Letters, 23(3), 745-759.

Reimann, M., Schilke, O., Weber, B., Neuhaus, C., \& Zaichkowsky, J. (2011). Functional magnetic resonance imaging in consumer research: A review and application. Psychology and Marketing, 28(6), 608-637.

Reimann, M., Zaichkowsky, J., Neuhaus, C., Bender, T., \& Weber, B. (2010). Aesthetic package design: A behavioral, neural, and psychological investigation.

Journal of Consumer Psychology, 20(4), 431-441.

Rilling, J. K., King-Casas, B., \& Sanfey, A. G. (2008). The neurobiology of social decisionmaking. Current Opinion in Neurobiology, 18(2), 159-165. Rilling, J. K., \& Sanfey, A. G. (2011). The neuroscience of social decision-making. Annual Review of Psychology, 62, 2348.

Rossiter, J. R., Silberstein, R. B., Harris, P. G., \& Nield, G. E. (2001). Brain-imaging detection of visual scene encoding in long-term memory for TV commercials.

Journal of Advertising Research, 41(2), 13-21.

Sanfey, A. G., Rilling, J. K., Aronson, J. A., Nystrom, L. E., \& Cohen, J. D. (2003). The neural basis of economic decision-making in the ultimatum game. Science,

300(5626), 1755-1758. 
Santos, J. P., Seixas, D., Brandão, S., \& Moutinho, L. (2012). Neuroscience in branding: A functional magnetic resonance imaging study on brands' implicit and explicit impressions. Journal of Brand Management, 19(9), 735-757.

Schaefer, M., Berens, H., Heinze, H. J., \& Rotte, M. (2006). Neural correlates of culturally familiar brands of car manufacturers. NeuroImage, 31(2), 861-865.

Schaefer, M., \& Rotte, M. (2007a). Favorite brands as cultural objects modulate reward circuit. Neuroreport, 18(2), 141-145.

Schaefer, M., \& Rotte, M. (2007b). Thinking on luxury or pragmatic brand products: Brain responses to different categories of culturally based brands. Brain

Research, 1165, 98-104.

Senior, C., Smyth, H., Cooke, R., Shaw, R. L., \& Peel, E. (2007). Mapping the mind for the modern market researcher. Qualitative Market Research: An

International Journal, 10(2), 153-167.

Smith, A. E., \& Humphreys, M. S. (2006). Evaluation of unsupervised semantic mapping of natural language with Leximancer concept mapping. Behavior

Research Methods, 38(2), 262-279.

Stallen, M., Smidts, A., Rijpkema, M., Smit, G., Klucharev, V., \& Fernández, G. (2010). Celebrities and shoes on the female brain: The neural correlates of product evaluation in the context of fame. Journal of Economic Psychology, 31(5), 802-811.

Stoll, M., Baecke, S., \& Kenning, P. (2008). What they see is what they get? An fMRI-study on neural correlates of attractive packaging. Journal of Consumer

Behaviour, 7(4-5), 342-359.

Sudman, S., \& Bradburn, N. M. (1973). Effects of time and memory factors on response in surveys. Journal of the American Statistical Association, 68(344),

$805-815$.

Tremblay, L., \& Schultz, W. (1999). Relative reward preference in primate orbitofrontal cortex. Nature, 398(6729), 704-708.

Vecchiato, G., Astolfi, L., De Vico Fallani, F., Cincotti, F., Mattia, D., Salinari, S., et al (2010). Changes in brain activity during the observation of TV commercials by using EEG, GSR and HR measurements. Brain Topography, 23(2), 165-179.

Vecchiato, G., Toppi, J., Astolfi, L., De Vico Fallani, F., Cincotti, F., Mattia, D., et al (2011). Spectral EEG frontal asymmetries correlate with the experienced pleasantness of TV commercial advertisements. Medical and Biological Engineering and Computing, 49(5), 579583. 
Solnais, C., Andreu-Perez, J., Sánchez-Fernández, J., \& Andréu-Abela, J. (2013). The contribution of neuroscience to consumer research: A conceptual framework and empirical review. Journal of Economic Psychology, 36, 68-81.

Wallis, J. D. (2007). Orbitofrontal cortex and its contribution to decision-making. Annual Review of Neuroscience, 30, 31-56.

Wang, Y. J., \& Minor, M. S. (2008). Validity, reliability, and applicability of psychophysiological techniques in marketing research. Psychology and Marketing,

25(2), 197-232.

Wise, R. A., \& Rompré, P. P. (1989). Brain dopamine and reward. Annual Review of Psychology, 40(1), 191-225.

Yoon, C., Gutchess, A. H., Feinberg, F., \& Polk, T. A. (2006). A functional magnetic resonance imaging study of neural dissociations between brand and person judgments. Journal of Consumer Research, 33(1), 31-40.

Young, C. (2002). Brain waves, picture sorts , and branding moments. Journal of Advertising Research, 42(4), 42-53. 